Meeting in Victorio

\title{
Canadian Institute of Forestry Policy for Selection, Protection and Management of Natural Areas
}

\section{Introduction}

\section{Definition}

A natural area is a naturally occurring physical or biological unit where natural conditions are maintained insofar as possible. An area is preserved to exemplify typical or unique vegetation and its associated biotic, edaphic, geologic and aquatic features in as near-natural condition as possible, usually by allowing the ordinary physical and biological processes to operate without human intervention.

\section{Objectives}

Natural areas can serve one or more of the following purposes:

1. Science. To provide outdoor laboratories for the study of natural processes in relatively undisturbed ecosystems by biologists, wildlife specialists, soil scientists, micro-climatologists, geomorphologists, and others in an environment that is relatively free of human intervention or that, through management practices when necessary, is maintained to preserve particular ecological conditions.

2. Benchmarks. Natural areas provide benchmarks against which land management practices can be gauged.

3. Preservation of gene pool resources. Natural areas will help to maintain the diversity present in natural ecosystems by the preservation of natural communities. They may also aid in conserving rare or endangered plants and animals in their natural habitat.

4. Education. Natural areas will serve as outdoor classrooms for the education of the increasing numbers who consider the primeval landscape a cultural heritage of intrinsic interest.

5. Living museum. Natural areas will preserve representative examples of forest vegetation in a state as nearly natural as possible, closely approximating conditions that existed at the time of settlement.

\section{Role of CIF}

The Canadian Institute of Forestry encourages reservation of a number of natural areas represent- ing examples of all significant forest and forestrelated vegetation in Canada. The Institute cooperates with other professional scientific and private groups - local, provincial, national, and international - to assure the creation and maintenance of such a system. The CIF does not own land; instead, it works through the affiliation of its members with public and private agencies who have jurisdiction over forest lands.

The CIF provides leadership in the following ways:

- prepares standards to guide selection, protection and management of representative natural areas in ecosystems that occur on or in association with forest lands.

- maintains an up-to-date national register of CIF-approved Natural Areas, periodically distributes the register to professional and scientific groups, and otherwise encourages scientific and educational use of the areas.

- identifies gaps in the system of forested natural areas and encourages public and private land managing agencies to set aside suitable tracts.

- operates a national committee which cooperates with national, regional and local agencies in carrying out the above functions.

\section{Selection}

\section{Classification and Size}

Forest Regions of Canada (J. S. Rowe, 1959, Can. Dep. Northern Affairs Nat. Res., Forest. Br. Bull. No. 123, 71 p.), serves as the overall classification system for forest vegetation. Representative areas of each forest cover type in each "Forest Section", as described by Rowe should be set aside as natural areas, wherever they constitute a significant portion of the forest section. Some cover types listed in Forest Cover Types of North America (Soc. Amer. Forest. 1953) may vary within and between Forest Sections. In such cases sub-types should be recognized. Liaison officers and their committee members, in consultation with the $\mathrm{Na}$ tional Natural Areas Committee, should determine 
the number of areas needed for adequate representation for each type.

The CIF must also be concerned about forestassociated vegetation. The Institute will work cooperatively with professional societies and with scientific and educational groups to be certain that examples are reserved of vegetation important for livestock or wildlife or for scientific investigations.

Although forested natural areas have traditionally been $300-1,000$ acres in size, some as small as 10 acres have been recognized. This 300-1,000 acre size continues to be a highly desirable goal, but increased competition for land makes it unattainable in heavily populated areas. Nevertheless, natural areas should be large enough to protect the ecosystem in question. If small, they should be buffered by suitable forested areas. Since natural areas are intended for permanent reservation, locations must be avoided that are threatened by growing communities and recreational and industrial developments, or by highway and reservoir construction.

The Institute is primarily interested in setting aside examples of all forest and forest-related vegetation. Highest priority should be given to reservation of natural areas: 1/ representing undisturbed examples of the major, commercially important forest types, and $2 /$ protecting rare and endangered species of plants and animals. Where typical undisturbed stands are not available, liaison officers should seek the least disturbed examples available, recognizing that the passage of time will bring them more nearly to natural conditions. The Institute is also interested in, and willing to cooperate with organizations involved in establishing natural areas in all terrestrial and aquatic ecosystems.

\section{Ownership}

Stable ownership and long-term protection is essential for natural areas. Liaison officers should first seek areas in provincial, federal and university custody since these organizations are generally in the best position to provide permanent reservation and long-term protection. Natural areas owned by such custodians should be designated by adequate administrative orders.

In many instances only private or corporate owners can provide representation of certain forest types. The private landowner or corporate officers ideally should, by will, covenant attached to the deed, or other legal means, stipulate that the natural area will be maintained inviolate. In lieu of this, a standard letter of agreement stipulating the responsibilities and liabilities of each party may be utilized. A reversionary clause may be inserted to provide for disestablishment of the natural area where the vegetation has been destroyed by conditions outside the control of the managing agency. Liaison officers should explore the possibility of donation of the tract to a public agency or university which can assure permanent protection.

\section{Description}

Basic ecological information on the plant and animal communities occurring in the natural areas should be collected. Such information is needed to provide a basis for management decisions. Photographs of the areas should be taken from specified locations.

\section{Protection}

\section{Identification}

The natural area should be identified in administrative records as to purpose and objectives. Consideration should be given to marking the boundary for the convenience of management and research personnel. Signs which would tend to attract sightseers, recreational and casual visitors should be avoided; however, if the roads or trails pass along the boundary or through the natural area, limited posting may be needed to minimize encroachments.

Natural areas vary greatly in size, composition and vulnerability. All areas should have a general management plan but for areas that have complex or unusual problems of protection and management liaison officers should encourage the preparation and periodic review of a detailed written plan to guide development and use.

\section{Fences}

Natural area boundaries may require fencing for protection against domestic livestock and other unwanted usage that would result in environmental changes. Fences may be needed for enclosing study plots.

\section{Publicity}

Publicity at national, regional, provincial, university, or local levels to inform professional research workers such as foresters, botanists, and zoologists, of the location, forest type, and administering agency, is essential in the interest of making proper use of the natural areas. Publicity that draws recreational visitors to the area, or otherwise infringes the scientific use of the area should be avoided.

\section{Physical improvements}

Physical improvements should be limited to unobtrusive trails, fences, and instrument and tool shelters needed for scientific and educational work. Except as essential to wildfire protection of adjoining lands, the construction of buildings, roads or recreational trails should be discouraged at or on the boundaries of a natural area.

Existing roads needed for administrative purposes, including the management of contiguous lands, or to facilitate research and which do not impair the function of a natural area, may be maintained; however, such maintenance, including the removal of dead and down timber should be limited to a strip not exceeding 30 feet either side of the center line of such roads. 
Fire, insects, and diseases

All wildfires originating within or adjacent to a natural area should be brought under control as quickly as possible. If a fire burns within an area, no cleanups, hazard reduction, nor reforestation should be undertaken unless the utility of the area has been so seriously impaired that it is no longer suitable as a natural area.

Insect or disease control may be necessary where the infestation seriously threatens adjacent areas or where other natural ecological processes will be disrupted.

\section{Mineral and oil entry}

These should be excluded entirely. However, certain practices, such as angular deep drilling for oil from adjacent properties, if there is good evidence that they will not effect the area, may be permitted.

\section{Management and Use}

\section{Vegetation management}

The guiding criterion for natural areas should be to maintain the ecosystem for which the area was designated in as nearly a natural state as possible. For each ecological reserve, the particular features to be preserved must be identified. Management criteria must be developed to protect those features of particular value.

Under these policies transitional forest and related vegetation may be maintained or created by such practices as prescribed burning to simulate wildfires, grazing or browsing by introduced wildlife to duplicate feeding habits of presettlement wildlife, and control of excessive wildlife by firearms or introduction of predators. The natural area must not be used to experiment with vegetation management methods - no treatment should be prescribed unless its efficacy has been unequivocally demonstrated by scientific investigation outside the natural area. If doubt exists about the need for vegetation management or the techniques available, then nothing should be done. If the area is large enough, a portion should be left on which to observe successional trends in the absence of vegetation management.

Restoration of conditions which existed prior to introduced disturbances may require manipulation. For example, after a long period of fire protection, it may be desirable to reduce litter accumulations by carefully controlled combustion so that a naturally fire-adapted vegetation formation can better survive wildfire.

Accidental destruction of part of a natural area through some introduced disturbance should ordinarily be followed by allowing natural processes to effect restoration. However, where there is evidence that such natural processes will be inadequate to prevent further deterioration through erosion or other influences, more direct action such as seeding or planting of native species may be employed. Such intervention should be done only after careful evaluation.

Introduction of exotic plant and animal species or artificial planting should be forbidden. Certain reintroductions of formerly occurring species may be permitted with the imposition of careful controls.

Wildlife populations ideally should be controlled by natural processes and no interference with normal cycles and fluctuations should be tolerated. Under some circumstances, predator removal and other disruptions of community relations may have created conditions under which certain species multiply beyond normal limits and thereby pose a disruptive threat. When this happens, control of such populations may be necessary by artificial means. Artificial practices may also be required to selectively control or eliminate populations of exotic species.

\section{Use of natural areas}

Scientific and educational use of natural areas must be essentially observational in character. Collection of soil samples, increment cores, and plant and animal specimens, and related work that is nondestructive or easily repaired is permitted. Manipulative experimental work (not to be confused with vegetation management where techniques are proven) involving such activities as timber felling, prescribed burning, or grazing is prohibited. In order to protect both the natural environment and the work of the investigator, the owner or custodian of the land should be consulted, and will normally acknowledge the use of the area and restrictions thereon in writing.

Public use, such as picnicking, camping, berry, nut or herb gathering, plant collecting, hunting, fishing, and other uses may contribute to modification of a natural area and may otherwise impair or limit the value of a natural area for research and educational purposes. These uses should be discouraged or expressly prohibited if they represent a serious threat to the biotic community or to research workers, students, or their instruments or study plots. Prevailing regulations should be modified, if it is determined by competent professional authority that additional restrictions are necessary to provide for normal plant and animal populations, or for the safety and well-being or scientists and their work.

It may be advantageous on certain natural areas to develop a small portion of the area for interpretive purposes, such as a nature trail and sign which explains why the area is set aside and why recreational use of the area is restricted.

\section{Guiding source material}

Society of American Foresters' policy for selection, protection and management of natural areas. J. Forest. 69:36061./Policy standards for research natural areas. 5th Draft by J. D. Sullivan. Coop. State Res. Serv., USDA. 1971./ Observations on the Pacific Northwest federal natural area program by J. F. Franklin, F. C. Hall and C. T. Dyrness, 1971./Canadian Legislation for ecological reserves by R. T. Franson, Fac. Law, Univ. British Columbia, Vancouver, 1971. /Wilderness ecology: a method of sampling and summarizing data for plant community classification by L. F. Ohmann and R. R. Ream, USDA, Forest Serv., Res. Pap. NC-49, 1971. 